\title{
The need for concept of efficiency evaluation of security control at airports
} Roman Vokáč ${ }^{*}$, Sarah Van den Berg ${ }^{1}$

${ }^{1}$ Czech Technical University in Prague, Faculty of Transportation Sciences, Prague, Czech Republic

*Corresponding author: Czech Technical University in Prague, Faculty of Transportation Sciences, Horská 3, 12801 Prague, Czech Republic, Email: vokacrom@fd.cvut.cz

\section{Abstract}

There are many demands placed on centralized security checkpoints of passenger and cabin luggage. Among the most important rank requirements for high passenger satisfaction, assurance of high security check effectiveness and operational efficiency. These three base requirements, however, do not support each other and in some ways they even conflict. Other aspects influencing operational security control are ever increasing volumes of handled passengers and the efforts to reduce flight ticket prices. Operational efficiency evaluation and targeted control are supported by the possibility to assure specific basic requirements. These include assuring required amount of security control staff, on the right place and at the right time. In sequence, a concept of security control efficiency evaluation is needed for operational, tactical and strategic planning.

\section{Keywords}

airport; security control; operational efficiency

\section{Introduction}

Security control of passengers and cabin luggage at airports poses important part of departing passengers handling. It influences efficiency and quality of the handling process, passengers' satisfaction, loyalty and the price of offered services. Apart from assuring high level of passenger satisfaction, there are inherent requirements for achieving high level of security and operational efficiency. These requirements are conflict with each other. This paper presents approach to balancing individual requirements and assuring long-term sustainability of development with operational efficiency. The efficiency of airport security is currently being addressed particularly in the areas of deploying state-of-the-art technologies, enhancing passenger throughput, modeling and simulation for what-if scenarios, and generating passenger arrival intensity forecasts. An appropriate partial solution and support for the possibility of influencing operational efficiency is to create a comprehensive concept of operational efficiency evaluation of security checkpoints at the airport.

\section{Requirements for security control}

This section describes selected requirements applicable to security control. It deals with the issue of assuring high level of passenger satisfaction and simultaneously high level of security and operational efficiency. 


\subsection{Passenger satisfaction}

One of the possible approaches to passenger satisfaction is understanding the satisfaction as the difference between expected and actual situation, as perceived by the passengers [1]. Among the frequently evaluated parameters, there are airport cleanliness, toilets, presence of children's areas and similar. Important part of the evaluated criteria is also security control of passengers. Passengers' loyalty and their willingness to return to the airport is an important indicator in current competitive environment of European airports. It depends for instance on the airport image, passengers' satisfaction or quality and price of the offered services [2]. There are several professional articles and publications dealing with the issue of passengers' satisfaction, from many different points of view (see $[3,4,5,6,7])$. High number of articles dealing with the issues underlines the importance of passenger satisfaction during the handling process and for all involved companies. Happy passengers are willing to spend more in airport commercial areas, they better cooperate with security control staff and similar. In the Czech Republic, Europe and world-wide, there is ever increasing trend of handled passengers. The International Air Transport Association deals with estimation of the traffic growth considering passenger numbers (see Fig. 1) and its forecasts support the claim.

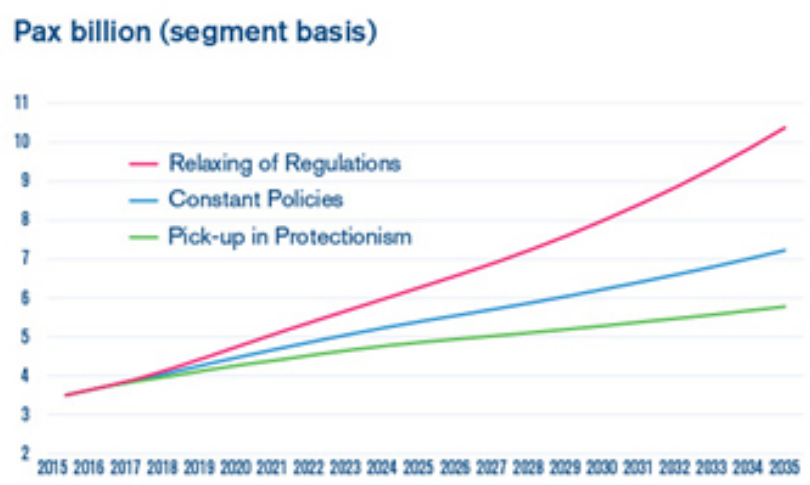

Figure 1. IATA forecast of passenger growth [8]

Even when considering pessimistic development (connected with reduction of trade liberalization and pick-up in trade protectionism, Fig. 1), the number of passengers is expected to grow in the long-term [8]. The increased number of handled passengers by security control brings about higher demands on quality of the provided services and process efficiency. With ever increasing intensity of passengers' arrival, especially during rush hours, maximum capacity of airport terminals may be achieved and maintained over some periods. Security checkpoints are no exception from this. With this condition, the handling process starts to produce queues and delays. In sequence, passenger satisfaction drops quickly, affecting the economic part of handling $[9,10]$. If the service provision doesn't meet input requirements, the risk of economic losses increases and so as the risk of externalities related to delayed passenger handling.
Current trends in income show high share of side activities (e.g. renting commercial premises) in the airport profit [11]. Overall income distribution of selected U.S. airports during 2012 is shown in Fig. 2. The level of income from side activities is influenced, among other things, by the passenger satisfaction.

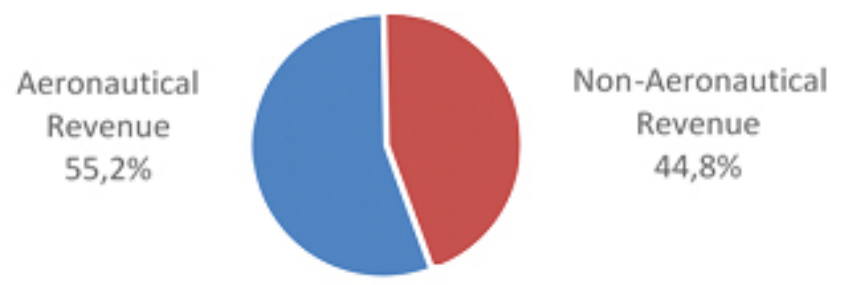

Figure 2. U.S. airports distribution of income during 2012 [12]

Security control has also significant influence on the passengers' stress level and their resulting satisfaction, as shown by Bouraï in 2012 (see Fig. 3) [13].

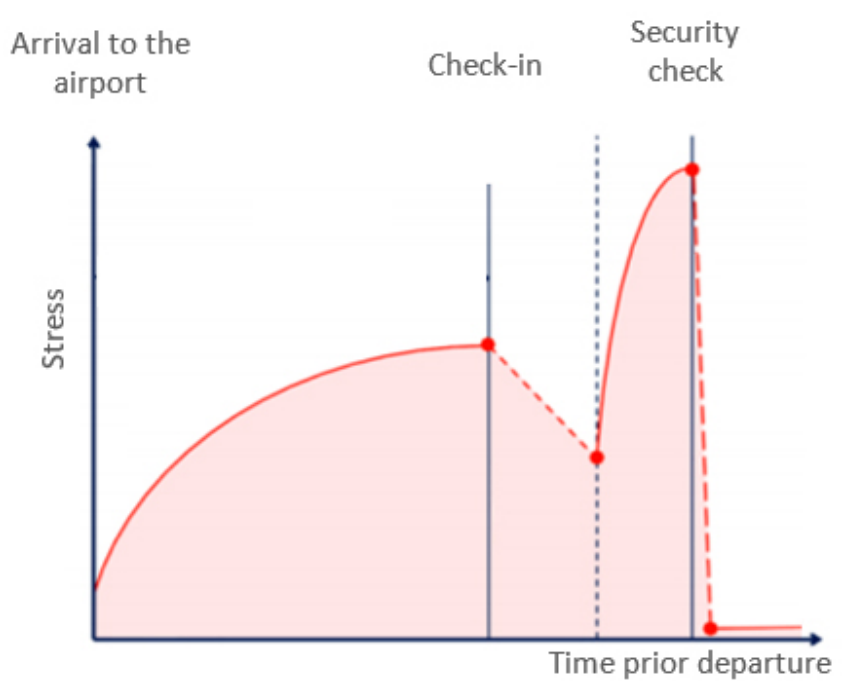

Figure 3. Passengers'stress level during security check process [13]

Security control has clearly significant influence on passenger satisfaction and the level of their stress. The requirement on high level of satisfaction is given by the effort to increase their loyalty, willingness to cooperate and follow the instructions of security control staff. This leads to expedited handling process so as to increased willingness of passengers to spend money in airport commercial zones.

\subsection{Security}

Regulatory framework determines the required level of security coupled with security control procedures at airports. The need for maximum security is not only stipulated, but it is also in the interest of all companies operating in the airport area. After a commitment of unlawful act and its media coverage, the demand for air transport drops immediately. The extent 
of negative influence is given by severity and publicity of an unlawful act.

Fig. 4 shows development of Revenue Passenger Kilometers (RPK) during the years 2010 to 2017. After the terrorist attacks in Paris during 2015 and at Brussels airport in 2016, RPK has been negatively influenced.

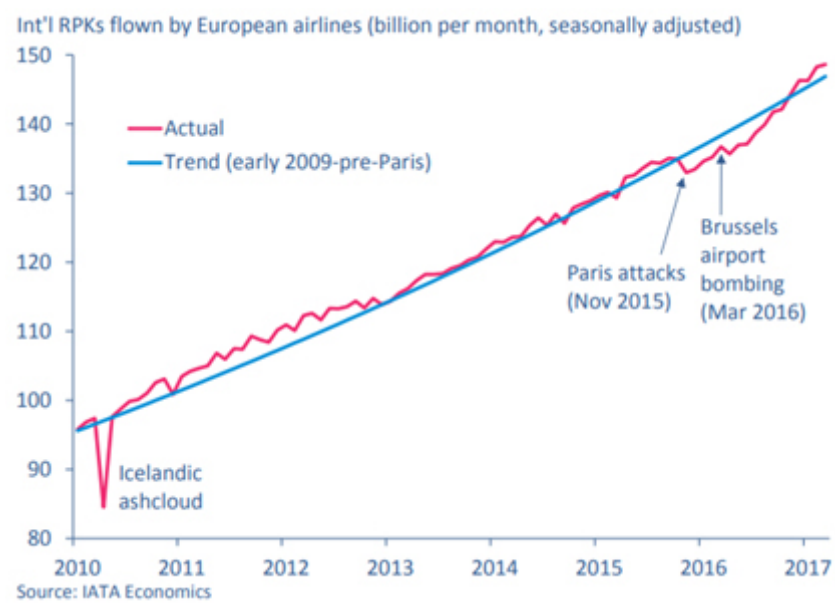

Figure 4. Int'l RPKs (Revenue Passenger Kilometers ) flown by European airlines [14]

\subsection{Operational efficiency}

Air transport shows high growth of low-cost carriers [15]. This leads to the pressure to minimize air fare and correspondingly to maximizing efficiency of all activities while maintaining high level of passenger satisfaction and high level security. Assuring high level of operational efficiency has significant effect on costs and price of the offered services. Airports are commercial companies and generating profit is one of their primary goals. High level of security, passenger satisfaction and operational efficiency are only conditions and tools, which allow the airports to achieve long-term profit.

\section{The issue of assuring security control requirements}

When dealing with the issues of security control requirements regarding passengers and luggage checks, there are three conflicting areas balanced. The involve assuring the required level of security of air transport, required level of passenger satisfaction and operational efficiency. The issue is depicted in Fig. 5.

The domain of security is given by regulatory framework and achieving high level of security should be a priority of all security control operators. High level of passenger satisfaction is important for fluent handling process and increased airport income. The requirement for assuring high level of security and simultaneously high level of passenger satisfaction lays down high demands for operational efficiency.

To better understand the significance of operational efficiency, extreme cases with respect to the triangle in Fig. 5

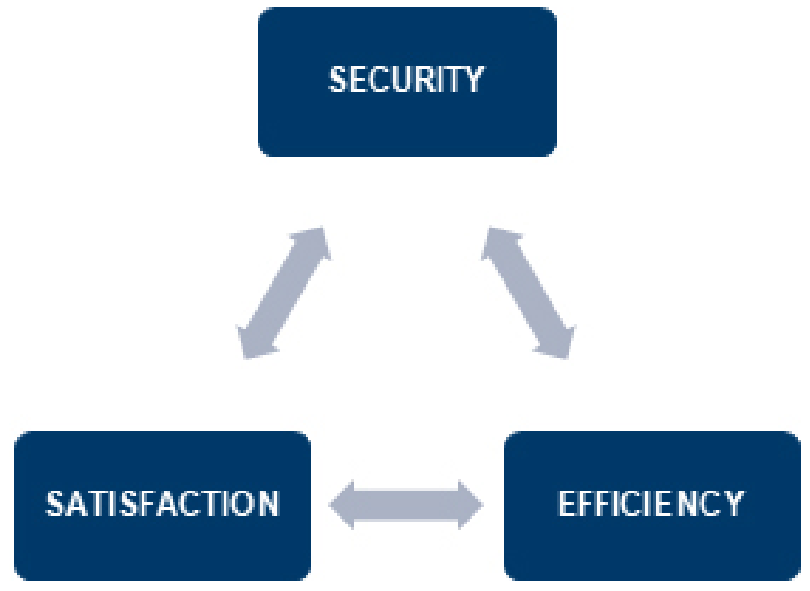

Figure 5. Security control requirements and their balance

can be used. If the goal would be maximum level of security regardless of other requirements, there would be long queues and waiting times due to extensive checks. Passenger satisfaction would be negatively influenced by the long waiting times and by the way security checks are carried out (infringing personal and intimate areas). By contrast, ideal situation from the perspective of passengers would be security assurance without the need to stay in queues so as fluent passage through the security checkpoints with no invasive checks associated with interaction and/or cooperation with security control staff. The requirement for high level of security then clearly conflicts with the requirement for passenger satisfaction and operational efficiency.

\section{Evaluation and control of operational efficiency}

Balancing all three requirements for security control is possible through targeted control of operational efficiency, while meeting required qualitative parameters (e.g. waiting time). Each qualitative parameter has its tools for evaluating success rate - security is evaluated by the means of audits and security tests, passenger satisfaction is evaluated by various methods of its inquiry.

Evaluation of operational efficiency is an issue, however. Unlike setting the priorities and evaluated criteria in the domain of security and satisfaction, these are not so simple to set for operational efficiency. Typically, the base measured parameter in this domain is passengers waiting time. This is, however, very simplified approach with no expressive value about the actual level of operational efficiency.

With respect to ever increasing number of departing passengers and jointly with the efforts to assure high level of security and passenger satisfaction, it is necessary to propose a concept for evaluation and control of operational efficiency of security control. 


\section{Conclusion}

With respect to the raising number of departing passengers and the conflicting requirements for maintaining high level of security and passenger satisfaction, it is necessary to propose new concept that would allow evaluation of operational efficiency in the processes of security control. The concept shall be based on developing models of arriving passengers' intensity and operational load of security checkpoints. The concept shall enable evaluation of anticipated operational load in comparison with actual data measured from operations, the efficiency of staff allocation to the security checkpoints so as the overall operational efficiency.

\section{Acknowledgments}

This paper was supported by the Grant Agency of the Czech Technical University in Prague, grant No. SGS18/095/OHK2/1T/16.

\section{References}

[1] Mk Ching. Passengers' perception on airport service and quality satisfaction. In Proceedings of International Academic Conferences, 2014.

${ }^{[2]}$ Ecem BASAK CALISIR, Nese and Fethi CALISIR. Key drivers of passenger loyalty: A case of frankfurt-istanbul flights. Journal of Air Transport Management, (53):211217, 2016. ISSN 0969-6997.

${ }^{[3]}$ R. VOKÁČ and S SZABO. Passengers' satisfaction as a key factor for airport bussiness and heading activities. In New Trends in Civil Aviation 2016, pages 112-114, 2016. ISBN 978-80-554-1252-8.

[4] George C.L. BEZERRA and Carlos F. GOMES. The effects of service quality dimensions and passenger characteristics on passenger's overall satisfaction with an airport. Journal of Air Transport Management, (44-45): 77-81, 2015. ISSN 0969-6997.

[5] LÁNSKÝ M. VOKÁČ́, R. and S SZABO. The dependence of airport profit on passenger satisfaction and operational efficiency. MAD - Magazine of Aviation Development, 5(2):11-14, 2017. ISSN 1805-7578.

[6] Debbie NIEMEIER GKRITZA, Konstantina and Fred MANNERING. Airport security screening and changing passenger satisfaction: An exploratory assessment. Journal of Air Transport Management, 12(5):213-219, 2006. ISSN 0969-6997.

[7] Woo Gon KIM ALI, Faizan and Kisang RYU. The effect of physical environment on passenger delight and satisfaction: Moderating effect of national identity. Tourism Management, (57):213-2224, 2016. ISSN 0261-5177.
[8] IATA. Iata forecasts passenger demand to double over 20 years. 2016. URL http://www.iata. org/pressroom/pr/Pages/2016-10-1802 . aspx.

[9] Alan (Avi) KIRSCHENBAUM. The cost of airport security: The passenger dilemma. Journal of Air Transport Management, (30):39-45, 2013. ISSN 0969-6997.

[10] LIPTÁK T. VOKÁČ, R. and M. LÁNSKÝ. The importance of queues at airport security checkpoints. In New Trends in Aviation Development 2016, 2016. ISBN 978-80-553-2628-3.

[11] ACI Airport Council International. Non-aeronautical revenue. 2013. URL http://www.aci-na.org/ sites/default/files/non-aeronautical_ revenue-september2013.pdf.

[12] Cindy NICHOL. Innovative finance and alternative sources of revenue for airports. Transportation Research Board, 2007. ISBN 0309097835.

[13] Erick BOURAII. Aviation security: Thinking ahead. In Passenger Terminal Conference 2015, 2015.

[14] IATA. Estimating the impact of recent terrorist attacks in western europe. 2017. URL https: / / www. iata. org/publications/economic-briefings/ European-terrorism-impact.pdf.

[15] ICAO. Low cost carriers (lccs). URL https://www.icao.int/sustainability/ Pages/Low-Cost-Carriers.aspx. 